Research Paper

\title{
PD-1-positive Natural Killer Cells have a weaker antitumor function than that of PD-1-negative Natural Killer Cells in Lung Cancer
}

\author{
Chao $\mathrm{Niu}^{1 *}$, Min $\mathrm{Li}^{*}$, Shan $\mathrm{Zhu}^{2}{ }^{*}$, Yongchong Chen ${ }^{1}$, Lei Zhou ${ }^{1}$, Dongsheng $\mathrm{Xu}^{1}$, Jianting $\mathrm{Xu}^{1}$, Zhaozhi $\mathrm{Li}^{1}$, \\ Wei $\mathrm{Li}^{1}$, Jiuwei Cui ${ }^{\circledR}$ \\ 1. Department of Cancer Center, The First Hospital of Jilin University, Changchun 130021, China. \\ 2. Department of Translational Medicine, The First Hospital of Jilin University, Changchun 130021, China. \\ *Equal contributors. \\ $\square$ Corresponding author: Jiuwei Cui, The First Hospital of Jilin University, Changchun 130021, China. Tel: +86-43188782178; Fax: +86-43188782178; E-mail: \\ cuijw@jlu.edu.cn. \\ () The author(s). This is an open access article distributed under the terms of the Creative Commons Attribution License (https://creativecommons.org/licenses/by/4.0/). \\ See http://ivyspring.com/terms for full terms and conditions.
}

Received: 2020.05.02; Accepted: 2020.07.07; Published: 2020.07.19

\begin{abstract}
Antibodies targeting the immune checkpoint inhibitor, programmed cell death 1 (PD-1), have provided a breakthrough in the treatment of lung cancer. However, the function of PD-1 in natural killer (NK) cells of cancer patients remains unclear. Herein, we analyzed the expression of PD- 1 on the NK cells in the peripheral blood of patients with lung cancer and found that the level of PD-1+ NK cells in patients was significantly higher than that in healthy individuals. Moreover, these PD-1+ NK cells demonstrated a weaker ability to secrete interferon-gamma (INF- $\mathrm{Y}$ ), granzyme B, and perforin, and exhibited lower CD107a expression. Importantly, in patients with lung cancer, the percentage of PD-1+NK cells was significantly positively correlated with the concentration of IL-2 in the plasma, which was also higher than that in healthy individuals. In addition, IL-2 could increase the expression of PD-1 on NK cells in vitro, indicating that high IL-2 level in the plasma is largely responsible for the abundance of PD-1+ NK cells in patients with lung cancer. These findings demonstrate intriguing mechanisms for understanding the expression of PD-1 on NK cells and the function of PD-1+ NK cells in lung cancer. This study confirms and extends previous studies demonstrating that PD- 1 can negatively regulate the antitumor function of NK cells.
\end{abstract}

Key words: natural killer cells; programmed death-1; cytotoxicity; lung cancer

\section{Introduction}

Cancer is a major disease that has become a threat to human health in recent years. Lung cancer causes about $27 \%$ of all cancer deaths and has the highest morbidity and mortality among malignant diseases worldwide [1, 2]. Immune checkpoint inhibitor, programmed death (PD)-1, is mainly expressed on the membranes of activated $\mathrm{T}$ cells and monocytes [3]. PD-1 performs an essential function in the tumor immune escape [4-7]. The main ligand of PD-1 is program death ligand-1 (PD-L1), which is expressed not only on the membrane of normal cells but also of lung cancer cells [8]. By blocking the interactions of PD-1 and PD-L1, the immune system can be reactivated to fight lung cancer [7]. PD-1 inhibitors, such as pembrolizumab and nivolumab, have been approved by regulatory authorities for the treatment of non-small cell lung cancer [9, 10]. Although therapeutic strategies targeting the interactions of PD-1 and PD-L1 have recently shown promising clinical outcomes in lung cancer, challenges remain. Not all patients will benefit from these antibody drugs, and the mechanism still requires further investigations.

Immune cell therapy is a vital part of tumor therapy. Natural killer (NK) cells are critical innate immune cells [11], which can directly kill tumor cells 
by secreting perforin and granzyme and through an antibody-dependent cell-mediated cytotoxicity effect [12]. They can also inhibit the proliferation of tumor cells by secreting interferon-gamma (IFN- $\gamma$ ) [13]. NK cells play an essential role in lung cancer progression; the infiltration of NK cells in tumor tissues is related to a favorable prognosis in patients with lung cancer [14-16]. Moreover, the cytotoxicity and IFN- $\gamma$ secretion abilities are significantly lower in peripheral blood NK cells from patients with lung cancer than in controls [17]. Hence, exploring the mechanisms of NK cell dysfunction is very meaningful for the treatment of lung cancer.

PD-1 mediates the functional defects in NK cells found in some cancers, such as Kaposi sarcoma and multiple myeloma [18-20]. Blocking signal transmission between PD-1 and PD-L1 has been shown to restore the antitumor function of NK cells $[21,22]$. However, the characteristics of $\mathrm{PD}-1^{+} \mathrm{NK}$ cells in lung cancer have not been evaluated. Therefore, whether the dysfunction of NK cells is associated with PD-1 expression in lung cancer requires deep investigation.

Recently, extensive studies on the functions of various cytokines in tumor development have been performed. The concentration of IFN- $\gamma$ in plasma has been related to the response to PD-1 inhibitors in lung cancer, indicating that cytokines may be pivotal for the development of lung cancer [23]. Whether plasma cytokines in lung cancer patients will affect the expression of PD-1 in NK cells, and whether they are related to NK cell dysfunction are worth extensive studies.

Therefore, in this study, we determined the ratio of PD- $1^{+}$NK cells and the level of cytokines in the plasma of lung cancer patients and ascertained their correlation. We also evaluated the antitumor functions of PD- $1^{+}$NK cells.

\section{Materials and methods}

\section{Volunteer enrollment}

After our hospital's ethics committee approved the study, sixteen newly diagnosed lung cancer patients and sixteen healthy adult volunteers were enrolled, and informed consent was obtained from all participants. In order to avoid the effect of the age and gender, the age and gender of the healthy adult volunteers are matched with that of lung cancer patients. Additionally, the study strictly complied with the Declaration of Helsinki. The characteristics of all participants are listed in Table 1 and Table 2, respectively.

\section{Phenotypic analyses of blood cells}

Peripheral blood of all participates was extracted using heparin anti-coagulation venipuncture tubes. Blood $(200 \mu \mathrm{L})$ was incubated with mouse mAbs against human CD56 (FITC), CD3 (PerCP) (BD Biosciences, San Jose, CA, USA), and PD-1 (APC) (BioLegend, San Diego, CA, USA) for $15 \mathrm{~min}$ at $23^{\circ} \mathrm{C}$. The control groups were stained with isotypematched antibodies. Red blood cell lysis buffer was added to the tubes containing red blood cells to lyse them. After incubating at $23{ }^{\circ} \mathrm{C}$ for $5 \mathrm{~min}$ and one wash with PBS, cells were detected using a BD FACSCalibur cell analyzer (BD Biosciences). Data was then analyzed using FlowJo software (Tree Star Inc., Ashland, OR, USA).

Table 1. Characteristics of lung cancer patients

\begin{tabular}{lllll}
\hline Patient No. & Sex & Age (years) & Type of Tumor & Stage of Disease \\
\hline 1 & Male & 70 & Adenocarcinoma & T2aN2M0 IIIA \\
2 & Female & 66 & Adenocarcinoma & T4N2M1a IV \\
3 & Male & 52 & Adenocarcinoma & T2aN2M0 IIIA \\
4 & Male & 40 & Squamous carcinoma & T2aN2M0 IIIA \\
5 & Male & 63 & Adenocarcinoma & T2N2M1 IV \\
6 & Male & 60 & Adenocarcinoma & T3N3M0 IIIB \\
7 & Female & 51 & Adenocarcinoma & T4N2M0 IIIB \\
8 & Male & 68 & Adenocarcinoma & T4N2M1a IV \\
9 & Female & 65 & Adenocarcinoma & T2aN2M0 IIIA \\
10 & Female & 45 & Adenocarcinoma & T2aN2M0 IIIA \\
11 & Female & 62 & Adenocarcinoma & T2aN2M1b IV \\
12 & Male & 43 & Adenocarcinoma & T4N2M0 IIIB \\
13 & Female & 53 & Adenocarcinoma & T2aN2M0 IIIA \\
14 & Male & 53 & Adenocarcinoma & cT2aN2M0 IIIA \\
15 & Male & 48 & Adenocarcinoma & pT2N0M0 IB \\
16 & Male & 52 & Adenocarcinoma & pT2bN1M0 IIB \\
\hline
\end{tabular}

Table 2. Characteristics of healthy donors

\begin{tabular}{lll}
\hline Donor No. & Sex & Age (years) \\
\hline 1 & Female & 65 \\
2 & Female & 67 \\
3 & Male & 48 \\
4 & Male & 52 \\
5 & Male & 59 \\
6 & Female & 45 \\
7 & Female & 70 \\
8 & Male & 69 \\
9 & Male & 50 \\
10 & Male & 61 \\
11 & Female & 50 \\
12 & Female & 57 \\
13 & Female & 48 \\
14 & Male & 57 \\
15 & Male & 46 \\
16 & Male & 54 \\
\hline
\end{tabular}

\section{Isolation of peripheral blood mononuclear cells}

After separation from blood cells via centrifugation at $1,800 \times g$ and $23{ }^{\circ} \mathrm{C}$ for $10 \mathrm{~min}$, the plasma was collected for cytokine detection. Blood cells were suspended in normal saline and centrifuged at $800 \times g$ and $23{ }^{\circ} \mathrm{C}$ for $30 \mathrm{~min}$ to obtain 
peripheral blood mononuclear cells (PBMCs) using Ficoll (Nycomed Pharma AS, Oslo, Norway).

\section{Cytotoxicity assay}

K562 cells were labelled with Calcein-AM (Dojindo Laboratories, Kumamoto, Japan) at $37^{\circ} \mathrm{C}$ for 30 min. After washing with PBS, $5 \times 10^{3}$ Calcein-AMlabelled K562 cells were added to a 96-well plate with $100 \mu \mathrm{L}$ RPMI-1640 medium (Gibco, Grand Island, NY, USA). PBMCs were added to the wells at effectortarget ratios of 20:1 in $100 \mu \mathrm{L}$ medium. Spontaneous release was obtained by incubating the target cells in medium alone, and maximum release was obtained after treatment with 1\% Triton X-100. All experiments were performed in triplicate wells. Cytotoxicity was calculated according to the following formula: [(experimental release - spontaneous release)/ (maximum release - spontaneous release)] $\times$ $100 \%[24]$.

\section{PD-1 detection on cytokine stimulated NK cells}

PBMCs were incubated with or without interleukin (IL)-2 for 2 days. The cells were then incubated with mouse mAbs against human CD56 (FITC), CD3 (PerCP), and PD-1 (APC). The control groups were stained with isotype-matched antibodies. After one wash with PBS, the cells were detected by the FACSCalibur cell analyzer. The data were analyzed as above.

\section{Plasma cytokine analysis}

Plasma from all participants was measured in duplicate wells using the Milliplex human cytokine/ chemokine 96-well plate assay (Millipore, Billerica, MA, USA). The plates were read on a Luminex 200 analyzer (Luminex Corporation, Austin, TX, USA). Five analytes were measured: IL-2, tumor necrosis factor-alpha (TNF-a), IL-10, IFN- $\gamma$, and IL-6.

\section{Intracellular staining analysis}

Intracellular staining was carried out according to the manual of the BD Cytofix/Cytoperm ${ }^{\mathrm{TM}}$ kit (BD Biosciences). Briefly, PBMCs were harvested and adjusted to $1 \times 10^{6}$ cells $/ \mathrm{mL}$. The cells were incubated with $0.1 \%$ GolgiStop (BD Biosciences) in an incubator for $4 \mathrm{~h}$. The cells were incubated with mouse mAbs against human CD56 (FITC), CD3 (PerCP), and PD-1 (APC). These were followed by intracellular staining with mouse mAbs against human perforin (PE), granzyme B (PE), or IFN-ץ (PE) (BD Pharmingen, San Jose, CA, USA), as well as the isotype control antibodies. After one wash with PBS, the cells were detected by the FACSCalibur cell analyzer. The data were analyzed as above.

\section{Degranulation assay}

As previously described, the expression of CD107a was used to assess the cytotoxicity ability of NK cells [25, 26]. PBMCs and K562 cells were incubated at a ratio of 10:1. A mouse mAb against human CD107a-PE (BD Biosciences) and an isotype control antibody were added to the cells. Following stimulation with K562 cells for 1 h, $0.1 \%$ GolgiStop was added. After another $3 \mathrm{~h}$ incubation, the cells were collected and stained with mouse $m A b s$ against human CD3 (PerCP), CD56 (FITC), and PD-1 (APC). After one wash with PBS, the cells were detected and analyzed as above.

\section{Statistical analysis}

The proportions of cells were analyzed and compared using the paired $t$-test or repeated measures ANOVA and Tukey's multiple comparison test. Spearman's test was used for correlation analysis. GraphPad Prism 5 software was used for data analysis (GraphPad Software, San Diego, CA).

\section{Results}

\section{Lung cancer patient NK cells exhibit diminished antitumor function}

NK cell proportions were similar between the lung cancer and healthy control groups (Fig. 1A and B). The number of peripheral blood NK cells in lung cancer patients was nearly the same as in the healthy donors $\left[(0.19 \pm 0.09) \times 10^{6}\right.$ cells $/ \mathrm{mL}$ vs. $(0.25 \pm 0.10) \times 10^{6}$ cells $/ \mathrm{mL}, p=0.1134$; Fig. $1 \mathrm{C}]$. The PBMCs from lung cancer patients and healthy donors were tested for NK cell cytotoxicity. The antitumor function of the lung cancer NK cells was significantly lower than that of the healthy donors $(9.88 \% \pm 4.66 \%$ vs. $15.04 \% \pm$ $5.42 \%, p=0.0071$; Fig. 1D).

\section{Lung cancer patients have high PD-1+ NK cell levels}

PD-1 is rarely expressed on the NK cells of healthy individuals $[19,20,22,27]$. We found that the lung cancer group exhibited higher PD-1 ${ }^{+} \mathrm{NK}$ cell levels than the healthy donors $(5.62 \% \pm 4.49 \%$ vs. $2.08 \% \pm 0.38 \%, p=0.0037$; Fig. $2 \mathrm{~A}$ and $2 \mathrm{~B}$ ). Additionally, CD56 dim NK cells in the peripheral blood of the lung cancer group exhibited a significantly higher level of PD-1 expression than that of the healthy donors $(6.11 \% \pm 5.07 \%$ vs. $2.14 \% \pm$ $0.42 \%, p=0.0055$; Fig. 2C). However, there was no difference in the percentage of PD- $1^{+}$CD56 bright $\mathrm{NK}$ cells between lung cancer group and healthy donors $(1.67 \% \pm 0.85 \%$ vs. $1.30 \% \pm 0.75 \%, p=0.2655)$. In the lung cancer group, the PD-1+ NK cells were mainly CD56 ${ }^{\text {dim }}$ NK cells, not CD56 bright NK cells $(6.11 \% \pm$ 
$5.07 \%$ vs. $1.67 \% \pm 0.85 \%, p=0.0024$; Fig. 2D). Moreover, the patients and healthy donors had the same ratios of PD-1 expression on $\mathrm{CD}^{+}{ }^{+} \mathrm{CD} 56^{+} \mathrm{NKT}$ cells $(21.79 \% \pm 12.01 \%$ vs. $23.01 \% \pm 16.74 \%, p=0.8155)$, $\mathrm{CD}^{-}{ }^{-} \mathrm{CD}^{-} 6^{-}$(both negative, BN) cells $(3.13 \% \pm 0.97 \%$ vs. $2.64 \% \pm 0.62 \%, p=0.1044)$, and $\mathrm{CD}^{+}{ }^{+} \mathrm{CD} 56^{-} \mathrm{T}$ cells $(37.64 \% \pm 7.09 \%$ vs. $32.57 \% \pm 12.69 \%, p=0.1727$; Fig. $2 \mathrm{E})$.

\section{PD-1+ NK cells exhibited diminished antitumor function and IFN-Y secretion compared to PD-1 ${ }^{-}$NK cells}

To quantify the antitumor function of PD-1 positive and negative NK cells against hematologic tumors, the CD107a degranulation and perforin and granzyme B levels were analyzed. Compared to PD-1NK cells, PD- $1^{+}$NK cells exhibited low levels of CD107a $(18.38 \% \pm 7.91 \%$ vs. $30.39 \% \pm 10.97 \%, p=$ 0.0004 ; Fig. $3 \mathrm{~A}$ and $3 \mathrm{~B})$, perforin $(36.37 \% \pm 10.39 \%$ vs. $85.02 \% \pm 6.82 \%, p<0.0001$; Fig. $3 \mathrm{C}$ and $3 \mathrm{D})$, and granzyme B $(72.08 \% \pm 14.39 \%$ vs. $94.70 \% \pm 3.89 \%, p=$ 0.0002; Fig. 3E and 3F) secretion, indicating that PD-1+ NK cells exhibited weaker antitumor activity. The

A

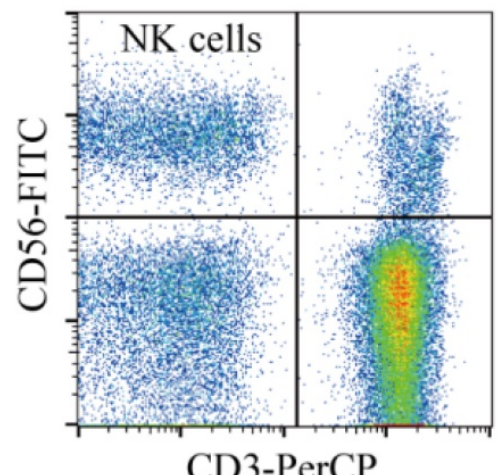

C

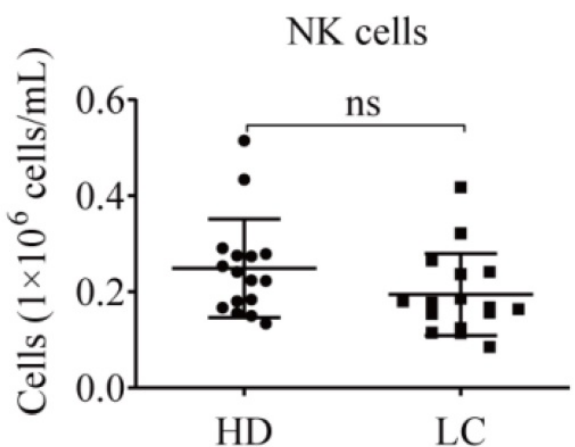

IFN- $\gamma$ percentages in PD-1 positive and negative NK cells were $47.35 \% \pm 14.12 \%$ and $63.96 \% \pm 15.98 \%$, respectively. PD- $1^{+}$NK cells demonstrated a weaker ability to secrete IFN- $\gamma$ than that of PD-1- NK cells (Fig. $3 \mathrm{G}$ and $3 \mathrm{H}$ ).

\section{PD-1+ NK cell level and IL-2 plasma concentration were positively related}

To analyze the relationship between PD- $1^{+} \mathrm{NK}$ cells and plasma cytokine concentrations, the plasma cytokine expression levels of all participants were detected. As a result, compared to the healthy donors, the patients exhibited higher levels of plasma IL-2 $(9.92 \pm 11.55 \mathrm{pg} / \mathrm{mL}$ vs. $2.21 \pm 2.28 \mathrm{pg} / \mathrm{mL}, p=0.0137$; Fig. $4 \mathrm{~A}), \mathrm{TNF}-\mathrm{a}(14.67 \pm 10.97 \mathrm{pg} / \mathrm{mL}$ vs. $8.30 \pm 1.60$ $\mathrm{pg} / \mathrm{mL}, p=0.0288$; Fig. $4 \mathrm{~B})$, and IL-10 (6.45 \pm 4.87 $\mathrm{pg} / \mathrm{mL}$ vs. $2.82 \pm 1.22 \mathrm{pg} / \mathrm{mL}, p=0.0070$; Fig. $4 \mathrm{C})$. However, the expression levels of IFN- $\gamma(1.31 \pm 0.87$ pg/mL vs. $0.74 \pm 1.09 \mathrm{pg} / \mathrm{mL}, p=0.1135$; Fig. $4 \mathrm{D})$ and IL-6 $(1.63 \pm 2.31 \mathrm{pg} / \mathrm{mL}$ vs. $0.53 \pm 0.60 \mathrm{pg} / \mathrm{mL}, p=$ 0.0750; Fig. 4E) in the patients were not significantly different from those of healthy donors.

B

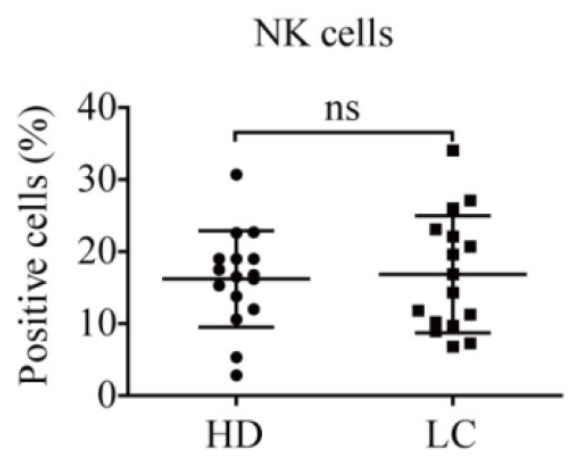

D

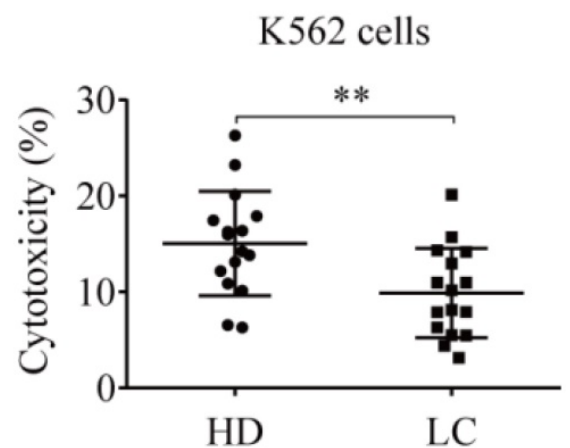

Figure 1. NK cells in lung cancer patients demonstrate reduced antitumor function. (A) Representative flow cytometry analysis of the expression levels of $\mathrm{CD}^{-} \mathrm{CD} 56^{+} \mathrm{NK}$ cells. (B) Graph showing the percentages of NK cells in the blood of lung cancer patients (LC) and healthy donors (HD). Data were analyzed and compared using the paired $t$-test; ns: not significant. (C) Numbers of NK cells in the peripheral blood of LC and HD. The absolute numbers of NK cells were obtained by multiplying PBMCs per milliliter of peripheral blood by the percentage of NK cells. Data were analyzed and compared using the paired $t$-test. ns: not significant. (D) Cytotoxicity of NK cells from LC and $\mathrm{HD}$ against K562 cells. Data were analyzed and compared using the paired $t$-test; $* * p<0.01$. 
A

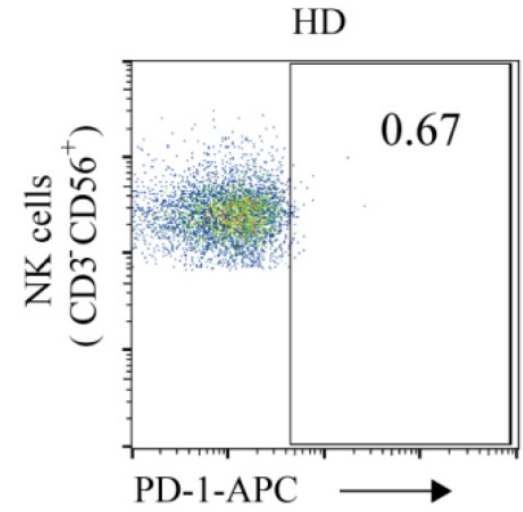

C

PD-1 on CD56 ${ }^{\text {dim }}$ NK cells

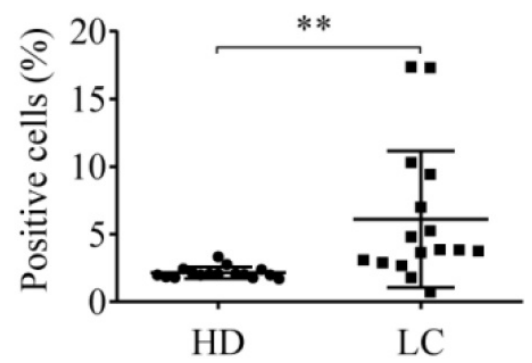

E

PD-1 on NKT cells

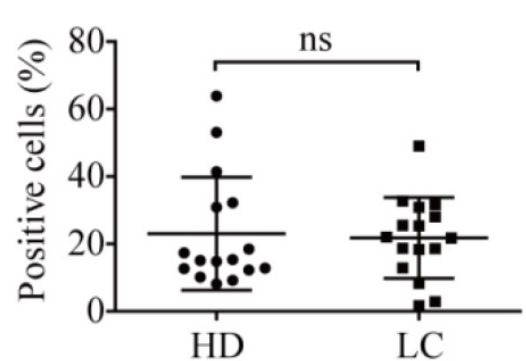

LC

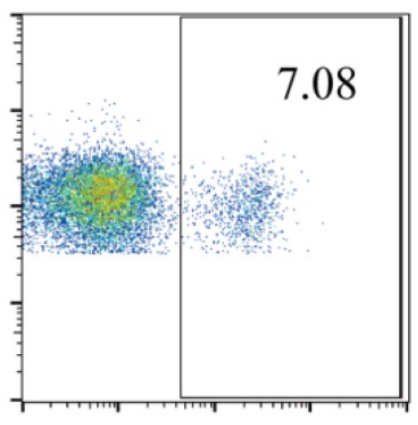

PD-1 on CD56 ${ }^{\text {bright }}$ NK cells

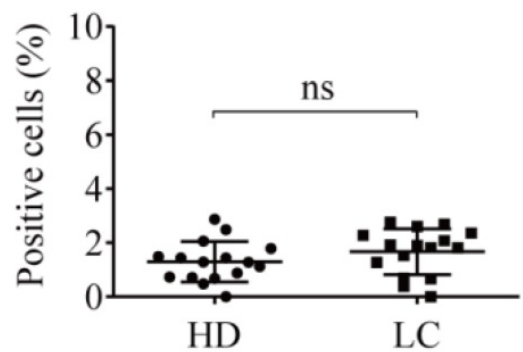

PD-1 on BN cells

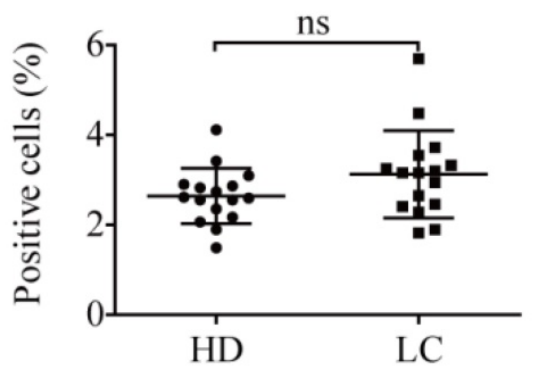

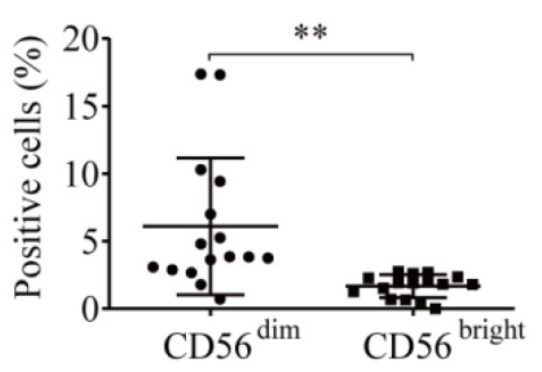

B

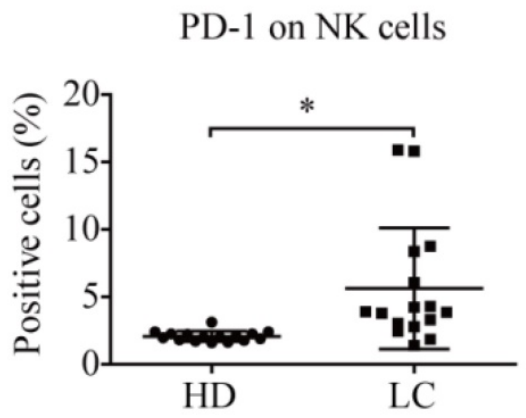

D

PD-1 on NK cells of LC

Figure 2. PD-1 expression in NK cells of lung cancer patients and healthy individuals. Peripheral blood of healthy donors and lung cancer patients was incubated with mouse mAbs against human CD56, CD3, and PD-1. After the lysis of red blood cells, the cells were analyzed by a flow cytometer. (A) Representative flow cytometry analysis of PD-1 expression on NK (CD3 $\left.{ }^{-} \mathrm{CD} 56^{+}\right)$cells in lung cancer patients (LC) and healthy donors (HD). (B) Graph showing the percentage of PD-1 expression on the NK cells of 16 $\mathrm{HD}$ and 16 LC. Data were analyzed and compared using the paired $t$-test; ${ }^{*} p<0.05$. (C, D) Graph showing the percentage of PD-1 expression on the CD56 dim NK cells and CD56bright NK cells of $16 \mathrm{HD}$ and 16 LC. Data were analyzed and compared using the paired $t$-test; **p < 0.01 , ns: not significant. (E) Graph showing the percentage of PD-1 expression on the $\mathrm{CD}^{+}{ }^{+} \mathrm{CD} 56^{+} \mathrm{NKT}$ cells, $\mathrm{CD}^{-} \mathrm{CD}^{-} 6^{-}$(both negative, $\mathrm{BN}$ ) cells, and T cells of $16 \mathrm{HD}$ and $16 \mathrm{LC}$. Data were analyzed and compared using the paired $t$-test. ns: not significant.

As for the correlation between plasma cytokine concentration and PD-1+ NK cells in lung cancer, a correlation analysis was conducted. The level of PD-1 ${ }^{+}$ NK cells was significantly positively related to the concentration of plasma IL-2 $(p=0.0013, r=0.6990$; Fig. 5A). However, there was no relation between the percentages of PD- $1^{+} \mathrm{NK}$ cells and the concentration of plasma IL-10 ( $p=0.4017, r=-0.0677$; Fig. $5 \mathrm{~B})$ or
TNF- $\alpha(p=0.4698, r=0.0206$; Fig. 5C).

\section{IL-2 increased NK cell PD-1 expression}

Compared to the PBS treatment group, IL-2 significantly elevated the ratio of $\mathrm{PD}-1^{+} \mathrm{NK}$ cells $(18.89 \% \pm 5.21 \%$ vs. $10.62 \% \pm 4.93 \%, p<0.001)$. This demonstrated that IL-2 could enhance the ratio of PD-1+ NK cells (Fig. 6A and 6B). 

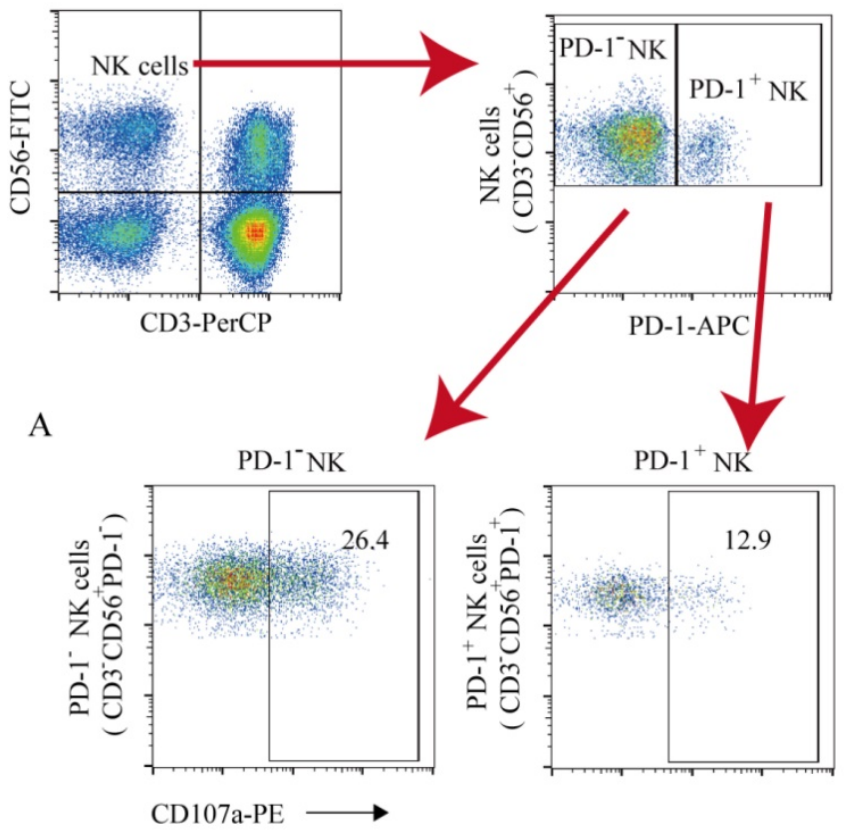

B
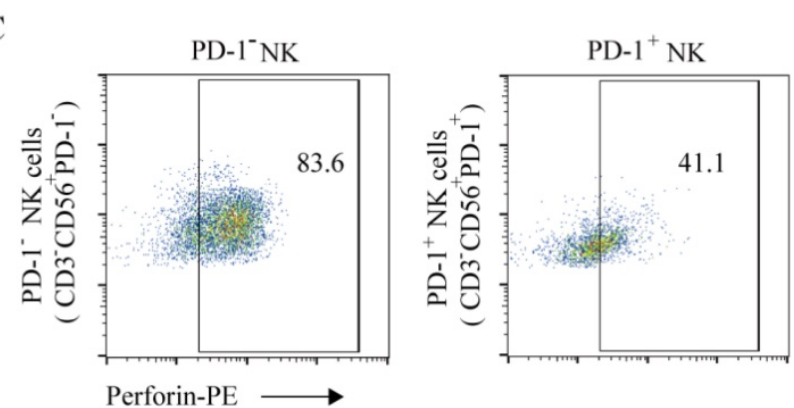

D

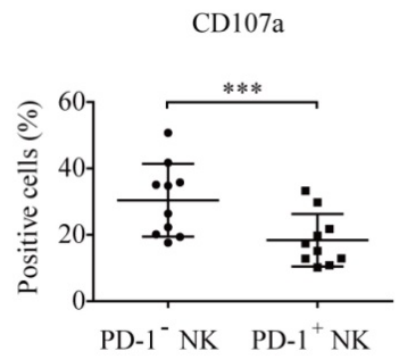

E
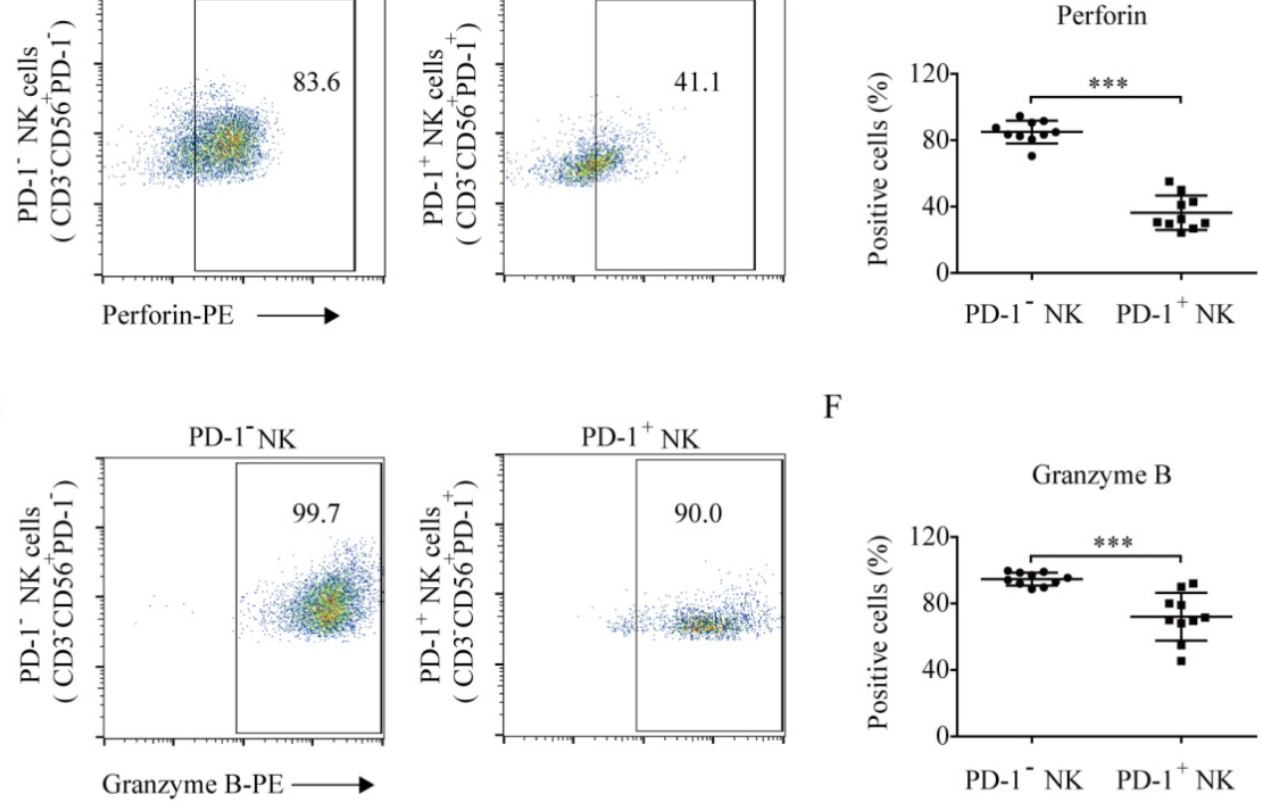

G
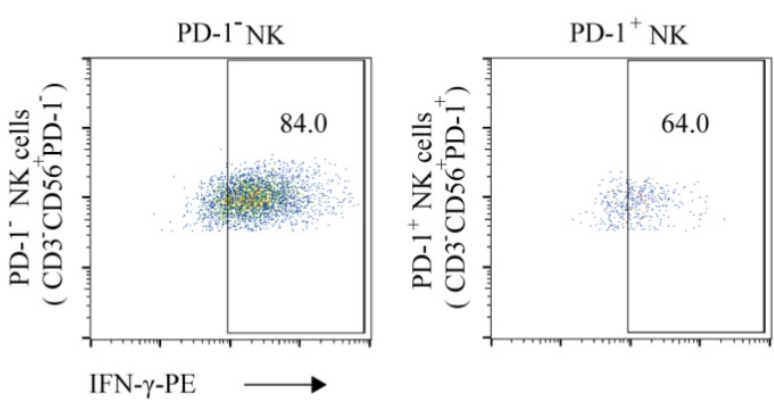

$\mathrm{H}$

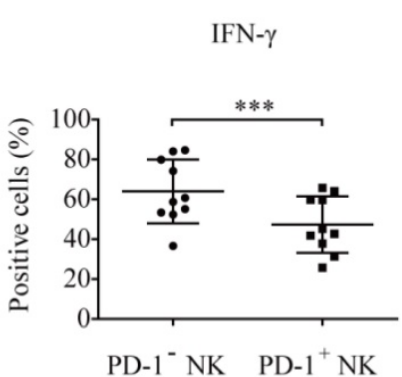

Figure 3. The levels of CDI07a, perforin, granzyme B, and IFN-y production in PD-1+and PD-1 ${ }^{-}$NK cells. The cells were collected, washed, and stained with CD56-FITC, CD3-PerCP, and PD-1-APC (to identify PD-1+ and PD-1 ${ }^{-}$NK cells) and with PE-labelled CDI07a, perforin, granzyme B, or IFN-y (to identify their expression in these cell populations). (A, C, E, G) Flow cytometry analysis of the PD-1+ and PD-1 $1^{-}$NK cells of one representative patient that were stained with (A) CDI07a-PE, (C) perforin-PE, (E) granzyme B-PE, (G) or IFN-y-PE. (B, D, F, H) Comparison of the expression of CDI07a, perforin, granzyme B, and IFN-Y in PD- $1^{+}$and PD-1 $1^{-}$NK cells in ten lung cancer patients who had a higher proportion of PD-1+ NK cells. Data were analyzed and compared using the paired $t$-test; $* * * p<0.001$. 
A

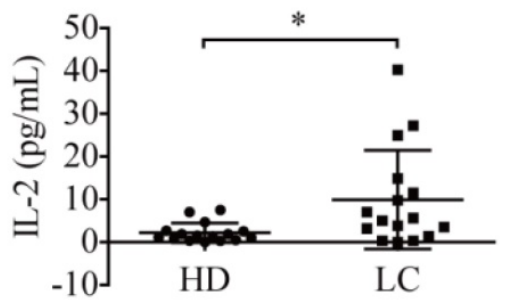

C

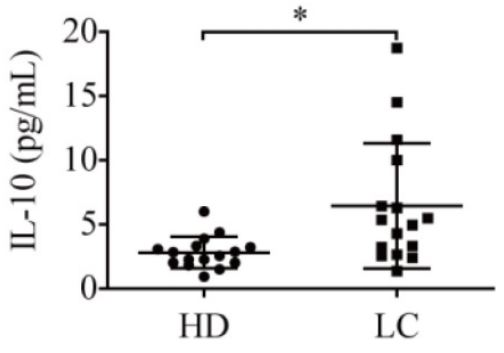

E

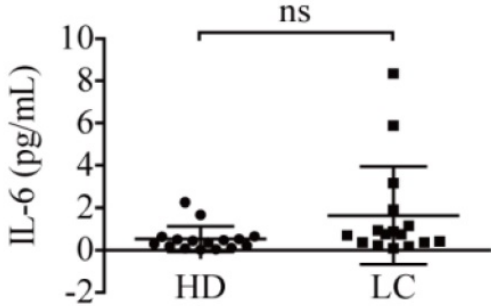

B

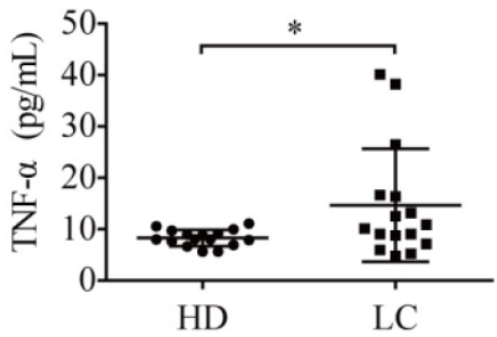

D

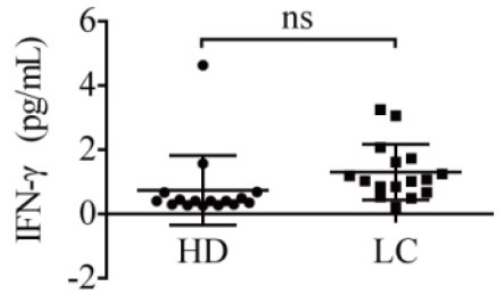

Figure 4. Plasma cytokines in lung cancer patients. Comparison of the concentrations of IL-2 (A), TNF- $\alpha$ (B), IL-10 (C), IFN-Y (D), and IL-6 (E) in the plasma of 16 lung cancer patients (LC) and 16 healthy donors (HD). Data were analyzed and compared using the paired $t$-test; ${ }^{*} p<0.05$; ns: not significant.

A

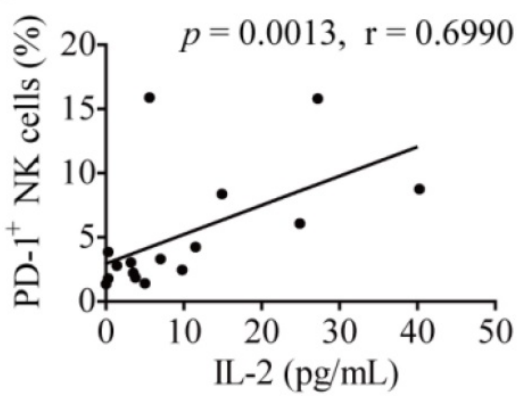

C

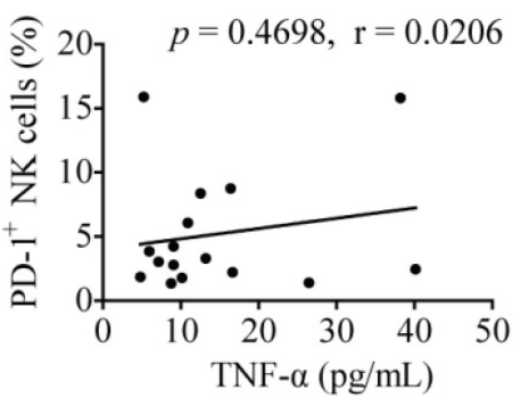

B

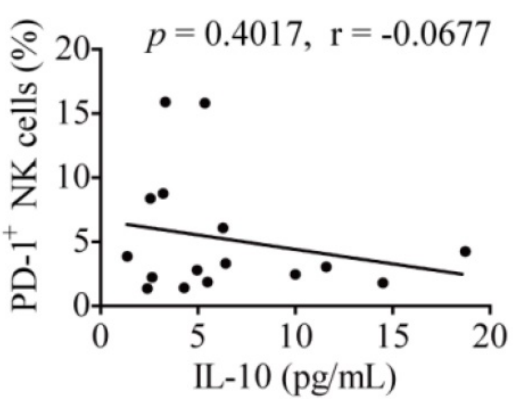

Figure 5. The correlation between plasma cytokine concentration and PD-1+ NK cells. (A-C) The plasma concentrations of IL-2, IL-10, and TNF- $\alpha$ of lung cancer patients (LC) were determined by the Miliplex human cytokine/chemokine 96 -well plate assay. Correlation analysis between plasma cytokine concentration and PD-1+ NK cells in LC was performed using Spearman's test. 
A

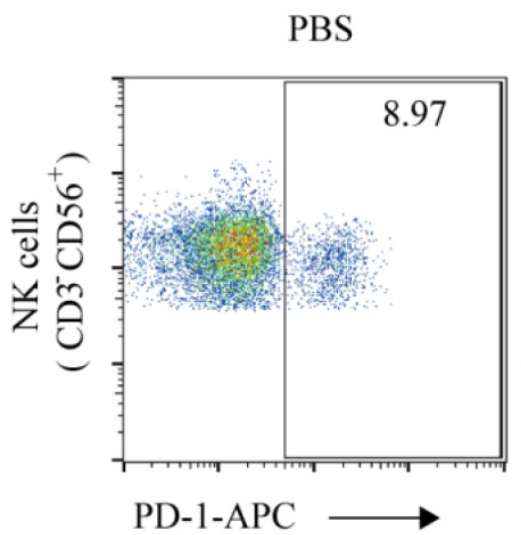

B

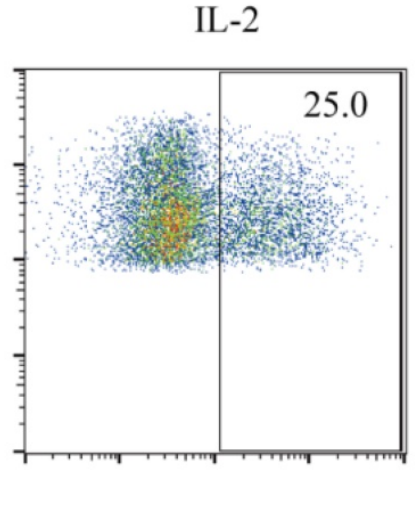

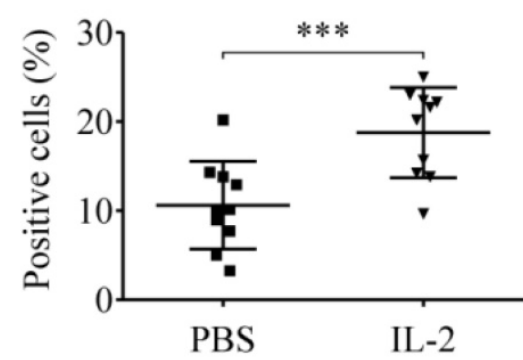

Figure 6. IL-2 enhanced PD-1 expression on NK cells. After treatment with PBS and $200 \mathrm{IU} / \mathrm{mL}$ IL-2 for $48 \mathrm{~h}$, peripheral blood mononuclear cells (PBMCs) were harvested and stained with CD56, CD3, and PD-1. (A) Representative flow cytometry analysis of the expression of PD-1 on NK cells cultured with PBS and IL-2 from one representative lung cancer patient. (B) Comparison of the expression of PD-1 on NK cells cultured with PBS and IL-2 from ten lung cancer patients. Data were analyzed and compared using the paired $t$-test; $* * * p<0.001$; ns: not significant.

\section{Discussion}

NK cells are natural immune cells, which perform an important function in tumor immunosurveillance [28, 29]. Solid tumors are reportedly characterized by decreased cell numbers and functional defects in NK cells $[17,30]$. We found that the antitumor function of NK cells in the peripheral blood of lung cancer patients was diminished compared to that in the healthy control donors, and the PD-1+ NK cell ratio in the lung cancer patients greatly exceeded that of the healthy individuals. More importantly, PD- $1^{+}$NK cells were less potent in secreting IFN- $\gamma$ and had lower antitumor effects than PD-1- $\mathrm{NK}$ cells, suggesting that the accumulation of $\mathrm{PD}-1^{+} \mathrm{NK}$ cells in lung cancer may be responsible for the dysfunction of NK cells. Although, the features of PD-1 in T cells have been thoroughly analyzed [31-34], its features on NK cells have not been explored extensively, and some findings from different tumor types are controversial. Some studies have shown that $\mathrm{PD}-1^{+} \mathrm{NK}$ cells are functionally defective $[19,20,35]$, whereas results of others suggest that they are activated NK cells $[36,37]$. In lung cancer, we found that perforin, granzyme B, IFN-Y, and CD107a were lower in PD- $1^{+}$NK cells than those in PD-1- NK cells. Hence, our findings support the theory that high PD-1 expression on NK cells counteracts the antitumor function of NK cells.

CD56 dim and CD56 bright NK cells are two subsets of NK cells. We observed that PD-1 was mainly expressed on the surface of CD56 dim NK cells from the patients of lung cancer, which is consistent with the findings in ovarian cancer and non-tumor infected patients [38]. In esophageal squamous cell carcinoma, the increased proportion of PD- $1^{+} \mathrm{NK}$ cells has been related to poor prognosis [20]. Therefore, we wanted to explore whether the enhanced percentage of peripheral blood PD-1+ ${ }^{+} \mathrm{NK}$ cells could be used as a prognostic indicator for lung cancer. Unfortunately, due to inadequate numbers of participants involved and insufficient observation time in this study, the relationship between PD- $1^{+}$NK cells and lung cancer prognosis could not be determined. Therefore, further studies should widen the scope of this meaningful comparative analysis.

The expression of PD- 1 on the T cell surface can be mediated by cytokines, such as IL-2 and IL-10 [39, 40]. Next, we asked whether the enhancement of PD- $1^{+}$NK cells in lung cancer associated with plasma cytokine. We demonstrated that the levels of IL-2, TNF- $a$, and IL-10 in the plasma from lung cancer patients were significantly higher than those in the plasma from healthy donors. Notably, in lung cancer, the concentration of plasma IL-2 was positively related with the proportion of PD- $1^{+} \mathrm{NK}$ cells in the blood. Moreover, in vitro studies have further indicated that IL-2 can quickly and significantly increase the $\mathrm{PD}-1^{+} \mathrm{NK}$ cell ratios of lung cancer patients; and similar results been confirmed in NK cells from healthy donors [22]. This suggests that the increased concentration of IL-2 in plasma from lung cancer patients may be one of the underlying reasons for the generation of PD-1+ NK cells in blood.

Given that the expression of CD107a has been considered as a sensitive marker for determination of the cytotoxic activity [41], to assess the cytotoxic activity of PD-1 ${ }^{+}$NK cells, we performed CD107a tests, rather than a cytotoxicity assay of NK cells on tumor cells. Insufficient quantity of PD- $1^{+} \mathrm{NK}$ cells from patients had been the primary limitation of the present study. Although the proportion of PD- $1^{+} \mathrm{NK}$ cells in lung cancer patients is higher than that in healthy individuals, it is still relatively low. To get 
enough PD-1 ${ }^{+}$NK cells for detection of cytotoxicity, approximately $1 \mathrm{~L}$ of peripheral blood per patient is needed, which is beyond the scope of responsible patient care. In future research, we plan to construct a NK cell line expressing PD-1 and conduct a thorough research on the antitumor effect of PD- $1^{+}$NK cells and the mechanisms underlying the PD-1 regulation of NK cell function.

\section{Conclusion}

In conclusion, this study reveals a subset of NK cells with high expression of PD-1 in the blood of the patients with lung cancer, and the abundant of these PD- $1^{+} \mathrm{NK}$ cells may be related to the increased concentration of IL-2 in the plasma of the patients. Moreover, the antitumor activity of PD- $1^{+}$NK cells is lower than that of PD-1- NK cells. These results further support the notion that PD-1 downregulates the antitumor effect of not only $\mathrm{T}$ cells but also NK cells. Given the importance of NK cells in antitumor immunity, our work provides a rationale for blocking the PD-1 and PD-L1 axis to rescue the dysfunction of NK cells in cancers including lung cancer.

\section{Abbreviations}

NK, natural killer; IL, interleukin; PD-L1, programmed cell death ligand-1; PD-1, programmed cell death 1 .

\section{Acknowledgments}

This work was supported by the National Key R\&D Program of China [grant number 2016YFC1303800]; National Natural Science Foundation of China [grant numbers 31700764, 31430021, and 81402436]; Jilin Provincial Key Laboratory of Biological Therapy [grant number 20170622011JC]; Jilin Provincial Science and Technology Department [grant numbers 20180101009JC 20200201180JC, and 20190303146SF]; Scientific and Technological Research of Jilin Provincial Education Department [grant number JJKH20190023KJ]; Jilin Province Finance Department [grant number 2018SCZWSZX-010]; Youth Fund of the First Hospital of Jilin University [grant number JDYY82017013]; Science and Technology Achievement Transformation Fund Project of the First Hospital of Jilin University [grant numbers JDYYZH-1902037 and JDYYZH-1902038], and China Guanghua Foundation \& First Hospital of Jilin University [JDYYGH2019004 and JDYYGH2019012].

\section{Authors' contributions}

JWC conceived and designed the study and revised the manuscript. WL participated in the design of the study. CN, SZ and ML conceived, designed, and carried out the studies and drafted the manuscript. YCC, LZ, DSX, JTX, and ZZL carried out part of the studies. All authors read and approved the final manuscript.

\section{Competing Interests}

The authors have declared that no competing interest exists.

\section{References}

1. Siegel RL, Miller KD, Jemal A. Cancer statistics, 2019. CA Cancer J Clin. 2019; 69: 7-34.

2. Thawani R, McLane M, Beig N, Ghose S, Prasanna P, Velcheti V, et al. Radiomics and radiogenomics in lung cancer: A review for the clinician. Lung Cancer. 2018; 115: 34-41.

3. Ceeraz. S, Nowak. EC, Noelle RJ. B7 family checkpoint regulators in immune regulation and disease. Trends Immunol. 2013; 34: 556-63.

4. Malhotra J, Jabbour SK, Aisner J. Current state of immunotherapy for non-small cell lung cancer. Transl Lung Cancer Res. 2017; 6: 196-211.

5. Helissey C, Champiat S, Soria JC. Immune checkpoint inhibitors in advanced nonsmall cell lung cancer. Curr Opin Oncol. 2015; 27: 108-17.

6. Cho JH. Immunotherapy for Non-small-cell Lung Cancer: Current Status and Future Obstacles. Immune Netw. 2017; 17: 378-91.

7. Raju S, Joseph R, Sehgal S. Review of checkpoint immunotherapy for the management of non-small cell lung cancer. Immunotargets Ther. 2018; 7: 63-75.

8. Wang. L, Ma. Q, Yao. R, Liu J. Current status and development of anti-PD-1/PD-L1 immunotherapy for lung cancer. International Immunopharmacology. 2020; 79: 106088.

9. Bylicki O, Barazzutti H, Paleiron N, Margery J, Assie JB, Chouaid C. First-Line Treatment of Non-Small-Cell Lung Cancer (NSCLC) with Immune Checkpoint Inhibitors. BioDrugs. 2019.

10. Mirabile A, Brioschi E, Ducceschi M, Piva S, Lazzari C, Bulotta A, et al. PD-1 Inhibitors-Related Neurological Toxicities in Patients with Non-Small-Cell Lung Cancer: A Literature Review. Cancers (Basel). 2019; 11.

11. Luna JI, Grossenbacher SK, Murphy WJ, Canter RJ. Targeting Cancer Stem Cells with Natural Killer Cell Immunotherapy. Expert Opin Biol Ther. 2017; 17: 313-24

12. Siu EHL, Chan AWH, Chong CCN, Chan SL, Lo KW, Cheung ST. Treatment of advanced hepatocellular carcinoma: immunotherapy from checkpoint blockade to potential of cellular treatment. Transl Gastroenterol Hepatol. 2018; 3: 15

13. Shevtsov M, Multhoff G. Immunological and Translational Aspects of NK Cell-Based Antitumor Immunotherapies. Frontiers in Immunology. 2016; 7.

14. Platonova S, Cherfils-Vicini J, Damotte D, Crozet L, Vieillard V, Validire P, et al. Profound coordinated alterations of intratumoral NK cell phenotype and function in lung carcinoma. Cancer Res. 2011; 71: 5412-22.

15. Carrega P, Morandi B, Costa R, Frumento G, Forte G, Altavilla G, et al. Natural killer cells infiltrating human nonsmall-cell lung cancer are enriched in CD56 bright CD16(-) cells and display an impaired capability to kill tumor cells. Cancer. 2008; $112 \cdot 863-75$

16. Jin S, Deng Y, Hao JW, Li Y, Liu B, Yu Y, et al. NK cell phenotypic modulation in lung cancer environment. PLoS One. 2014; 9: e109976.

17. Suliman Y Al Omar, Ernie Marshall, Derek Middleton, Christmas, SE Increased killer immunoglobulin-like receptor expression and functional defects in natural killer cells in lung cancer. Immunology 2011; 133: 94-104.

18. Bi JC, Tian ZG. NK Cell exhaustion. Frontiers in Immunology. 2017; 8: 10

19. Beldi-Ferchiou A, Lambert M, Dogniaux S, Vely F, Vivier E, Olive D, et al. PD-1 mediates functional exhaustion of activated NK cells in patients with Kaposi sarcoma. Oncotarget. 2016; 7: 72961-77.

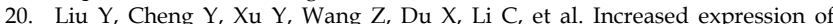
programmed cell death protein 1 on NK cells inhibits NK-cell-mediated anti-tumor function and indicates poor prognosis in digestive cancers. Oncogene. 2017; 36: 6143-53.

21. Dunai C, Murphy WJ. NK cells for PD-1/PD-L1 blockade immunotherapy: pinning down the NK cell. J Clin Invest. 2018.

22. Benson DM, Jr., Bakan CE, Mishra A, Hofmeister CC, Efebera Y, Becknell B, et al. The PD-1/PD-L1 axis modulates the natural killer cell versus multiple myeloma effect: a therapeutic target for CT-011, a novel monoclonal anti-PD-1 antibody. Blood. 2010; 116: 2286-94.

23. Boutsikou E, Domvri K, Hardavella G, Tsiouda D, Zarogoulidis K, Kontakiotis T. Tumour necrosis factor, interferon-gamma and interleukins as predictive markers of antiprogrammed cell-death protein-1 treatment in advanced non-small cell lung cancer: a pragmatic approach in clinical practice. Ther Adv Med Oncol. 2018; 10: 8

24. Niu C, Li M, Zhu S, Chen Y, Zhou L, Xu D, et al. Decitabine Inhibits Gamma Delta $\mathrm{T}$ Cell Cytotoxicity by Promoting KIR2DL2/3 Expression. Front Immunol. 2018; 9: 617 . 
25. Bryceson YT, Rudd E, Zheng C, Edner J, Ma D, Wood SM, et al. Defective cytotoxic lymphocyte degranulation in syntaxin-11 deficient familial hemophagocytic lymphohistiocytosis 4 (FHL4) patients. Blood. 2007; 110: 1906-15.

26. Niu C, Jin H, Li M, Zhu S, Zhou L, Jin F, et al. Low-dose bortezomib increases the expression of NKG2D and DNAM-1 ligands and enhances induced NK and gammadelta T cell-mediated lysis in multiple myeloma. Oncotarget. 2017; 8: 5954-64.

27. MacFarlane AW, Jillab M, Plimack ER, Hudes GR, Uzzo RG, Litwin S, et al. PD-1 Expression on Peripheral Blood Cells Increases with Stage in Renal Cell Carcinoma Patients and Is Rapidly Reduced after Surgical Tumor Resection. Cancer Immunology Research. 2014; 2: 320-31.

28. Bucklein V, Adunka T, Mendler AN, Issels R, Subklewe M, Schmollinger JC, et al. Progressive natural killer cell dysfunction associated with alterations in subset proportions and receptor expression in soft-tissue sarcoma patients. Oncoimmunology. 2016; 5: e1178421.

29. Imai K, Matsuyama S, Miyake S, Suga K, Nakachi K. Natural cytotoxic activity of peripheral-blood lymphocytes and cancer incidence: an 11-year follow-up study of a general population. Lancet. 2000; 356: 1795-9.

30. Tarazona R, Sanchez-Correa B, Casas-Aviles I, Campos C, Pera A, Morgado S, et al. Immunosenescence: limitations of natural killer cell-based cancer immunotherapy. Cancer Immunol Immunother. 2017; 66: 233-45.

31. Prado-Garcia H, Romero-Garcia S, Puerto-Aquino A, Rumbo-Nava U. The PD-L1/PD-1 pathway promotes dysfunction, but not "exhaustion", in tumor-responding $\mathrm{T}$ cells from pleural effusions in lung cancer patients. Cancer Immunol Immunother. 2017; 66: 765-76.

32. Simon S, Labarriere N. PD-1 expression on tumor-specific T cells: Friend or foe for immunotherapy? Oncoimmunology. 2017; 7: e1364828.

33. Zheng H, Liu X, Zhang J, Rice SJ, Wagman M, Kong Y, et al. Expression of PD-1 on CD4+ $\mathrm{T}$ cells in peripheral blood associates with poor clinical outcome in non-small cell lung cancer. Oncotarget. 2016; 7: 56233-40.

34. Li Y, Liang L, Dai W, Cai G, Xu Y, Li X, et al. Prognostic impact of programed cell death-1 (PD-1) and PD-ligand 1 (PD-L1) expression in cancer cells and tumor infiltrating lymphocytes in colorectal cancer. Mol Cancer. 2016; 15: 55.

35. Khan M, Arooj S, Wang H. NK Cell-Based Immune Checkpoint Inhibition. Front Immunol. 2020; 11: 167

36. Hsu J, Hodgins JJ, Marathe M, Nicolai CJ, Bourgeois-Daigneault MC, Trevino $\mathrm{TN}$, et al. Contribution of NK cells to immunotherapy mediated by PD-1/PD-L1 blockade. J Clin Invest. 2018.

37. Concha-Benavente F, Kansy B, Moskovitz J, Moy J, Chandran U, Ferris RL. PD-L1 Mediates Dysfunction in Activated PD-1(+) NK Cells in Head and Neck Cancer Patients. Cancer Immunol Res. 2018; 6: 1548-60.

38. Pesce S, Greppi M, Tabellini G, Rampinelli F, Parolini S, Olive D, et al. Identification of a subset of human natural killer cells expressing high levels of programmed death 1: A phenotypic and functional characterization. J Allergy Clin Immunol. 2017; 139: 335-46 e3.

39. Diller ML, Maio S, Eysmans GE, Lawson D, Delman KA, Kudchadkar RR, et al. High dose IL-2 (HDIL-2) results in increased PD-1 expression on CD45RA-CCR7-CD8+and CD45RA-CCR7-CD4+T cells in melanoma patients. Cancer Research. 2015; 75: 2.

40. Li C, Zuo W. IL-10 in vitro could enhance IFNgamma expression and suppress PD-1 expression in CD8 T cells from esophageal cancer patients. Exp Cell Res. 2019; 379: 159-65.

41. Aktas E, Kucuksezer UC, Bilgic S, Erten G, Deniz G. Relationship between CD107a expression and cytotoxic activity. Cell Immunol. 2009; 254: 149-54. 